\title{
TGR5 as New Target in Diabetes Care
}

\author{
Juei-Tang Cheng ${ }^{1 *}$, Chih-Chan Lin ${ }^{1}$ and Hsiao Yin Lien ${ }^{2}$ \\ ${ }^{1}$ Department of Medical Research, Chi-Mei Medical Center, Yong Kang, Tainan City, Taiwan 71003 \\ ${ }^{2}$ Department of Pharmacy, Veterans General Hospital, Kaohsiung City, Taiwan 81362
}

Submission: October 11, 2018; Published: December 13, 2018

*Corresponding author: Juei Tang Cheng, Department of Medical Research, Chi-Mei Medical Center, Yong Kang, Tainan City, Taiwan

\begin{abstract}
The bile acid binding receptor TGR5 is suitable as a new target for the handling in metabolic disorders, including type 2 diabetes, obesity, and fatty liver. TGR5 is known to express in various tissues, but the enterohepatic cycling limits bile acid to activate the receptors. The preclinical data demonstrated the merits of TGR5 activation in cases such as weight loss, glucose regulation, energy metabolism, and the lowering of inflammation. Studies in animals indicated the important role of Tgr5 in GLP-1 secretion, insulin sensitivity, and energy metabolism. However, evidence regarding these effects in clinical practice is still not enough. Therefore, we call the development of safe and selective TGR5 agonist(s) using the distinguished subtype of TGR5 in the near future.
\end{abstract}

Keywords: Bile acid; TGR5; GLP-1; Metabolism; Diabetes; Binding receptor; Metabolic disorders

Abbreviations: BAs: Bile Acids; FXR: Farnesoid X Receptor; TGR5: Takeda G Protein Receptor 5; PKA: Protein Kinase A; cAMP: Cyclic AMP; TLCA: Tauro-Lithocholic Acid; LCA: Lithocholic Acid; DCA: Deoxycholic Acid; CA: Cholic Acid; CDCA: Chenodeoxycholic Acid; UDC: Ursodeoxycholic Acid; T2DM: Type 2 Diabetes

\section{Introduction}

Bile acids (BAs) possess an amphipathic steroid molecule which may facilitate the intestinal absorption, emulsification, and transport of lipophilic nutrients and vitamins. Ba is mainly derived from the catabolism of cholesterol in the liver. Recently, BA has been introduced as the endogenous molecules showing pleiotropic responses [1], including glucose and energy homeostasis [2]. Some BAs scape the enterohepatic cycling to reach the systemic circulation [3]. Thus, they participate the functional processes such as lipid and glucose homeostasis, energy expenditure, intestinal mobility, inflammation [4], configuration, and the growth of gut microbiome or the skeletal muscle mass [5]. Dysregulated signaling of BAs have been indicated to involve in some disorders, including diabetes, obesity, dyslipidemia, fatty liver disease, atherosclerosis, cholestasis, gallstones, and cancer [6]. Basically, these effects of Bas were known to binding with the nuclear hormone farnesoid X receptor (FXR) and Takeda G protein receptor 5 (TGR5) in multiple organs [7]. In clinics, treatment of T2DM patients with the BA-like agent(s), or bariatric surgery in obese patients, results in a marked improvement in glycemic control that seems related with the changes in TGR5 and signaling. Therefore, we focus on the role of TGR5 in glucose homeostasis.

TGR5 belonged to G protein - coupled receptor that expressed in many tissues such as intestine, gallbladder, adipose tissues, skeletal muscle, brain, and pancreas. Therefore, TGR5 activated by BA induces the formation of the cyclic AMP (cAMP), which may activate protein kinase A (PKA) in cells and tissues [8]. Tauro-lithocholic acid (TLCA), lithocholic acid (LCA), deoxycholic acid (DCA), chenodeoxycholic acid (CDCA), and cholic acid (CA) can dose-dependently induce cAMP production in human TGR5transfected CHO cells. The rank order of potency (EC50) is TLCA $(0.33 \mu \mathrm{M})>\operatorname{LCA}(0.53 \mu \mathrm{M})>\operatorname{DCA}(1.01 \mu \mathrm{M})>\operatorname{CDCA}(4.43 \mu \mathrm{M})$ $>$ CA $(7.72 \mu \mathrm{M})$, as described previously [9]. However, CDCA, DCA, LCA, ursodeoxycholic acid (UDCA) may also activate FXR [10]. Otherwise, TGR5 is also activated by linolenic acid and oleanolic acid [11], in addition to ursolic acid [12] and glycyrrhizic acid [13]. Additionally, we demonstrated triamterene as the useful blocker of TGR5 [14].

Oral glucose administration induces a more pronounced insulin secretion than an isoglycemic intravenous injection Therefore, entero-endocrine $\mathrm{K}$ - and L-cells are identified and known to secrete the incretins, both glucose-insulinotropic polypeptide (GIP) and glucagon-like peptide (GLP)-1. After transcription and translation into proglucagon, the action of prohormone convertase $1 / 3$ in L-cells leads to GLP-1, GLP-2, oxyntomodulin, and IP2, whereas the action of prohormone convertase 2 in pancreatic $\alpha$-cells leads to glucagon, glicentinrelated polypeptide, IP1 and major proglucagon fragment [15]. In blood, GLP-1 half-life is about 1.5-5 min due to a rapid degradation by dipeptidyl peptidase 4 (DPP-4). Thus, DPP-4 inhibitors are successfully used to treat type 2 diabetes (T2DM) patients now. 
Activation of TGR5 promotes GLP-1 secretion from intestinal L cells due to a closure of the ATP-dependent potassium channel (KATP) and a higher mobilization of intracellular calcium to enhance GLP-1 secretion. Glucose also enhances GLP-1 biosynthesis and secretion. However, GLP-1 secretion by intestinal $\mathrm{L}$ cells is negatively regulated by FXR through inhibition of proglucagon gene expression and suppression of GLP-1 secretion through the interfering with pathways activated by glucose [16]. Therefore, BA activation of both TGR5 and FXR in intestinal L cells can induce opposite effects on GLP-1 secretion and production. However, TGR5 activation in L cells likely occurs rapidly after food ingestion, whereas activation of FXR induces a more delayed response that requires transcriptional activation. Otherwise, pancreatic $\beta$ cells express both TGR5 [17] and FXR [18], promoting glucose-stimulated insulin secretion by increasing intracellular calcium concentration. In pancreatic islet, TGR5 is identified in pancreatic $\alpha$ cells. Activation of TGR5 switches the $\alpha$ cell secretory phenotype from glucagon to GLP-1, thus promoting a paracrine effect on $\beta$ cells to stimulate insulin secretion [19].

T2DM is known as a heterogeneous group of disorders, characterized by a decline in insulin-producing pancreatic $\beta$ cells, an increase in peripheral insulin resistance, an increase in hepatic glucose production, or a combination of all the factors [20]. Therapies for T2DM are mostly focused on the reducing of hepatic glucose production, increasing of insulin secretion, and improving insulin sensitivity [21]. TGR5 as a receptor of bile acids has an effect on the regulation of glucose homeostasis. Activation of TGR5 could promote GLP-1 secretion in a murine enteroendocrine cell line STC-1 [8].

GLP-1 has the ability to enhance insulin secretion after oral administration of glucose. It suggested the potential treatment of T2DM through the management of glucose homeostasis by activatingTGR5. Additionally, TGR5 can induce cAMP-dependent thyroid hormone activating enzyme type 2 iodothyronine deiodinase, causing elevated energy expenditure in brown adipocytes and skeletal muscles [22]. TGR5 also induces differential translation of the $\mathrm{C} / \mathrm{EBPb}$ isoform by AKT-mTOR pathway in macrophages. Thus, activation of TGR5 can alter adipose tissue macrophage function to improve insulin action for treatment of T2DM [23]. Another mechanism possibly connecting TGR5 signaling and elevated energy expenditure via modifications in the gut microbiome [24]. Therefore, TGR5 activation for T2DM is not totally dependent on GLP-1 only. Moreover, TGR5 inhibits renal disease in obesity and diabetes through inducing mitochondrial biogenesis and preventing renal oxidative stress and lipid accumulation [25]. The new roles of TGR5 in obesity has also been documented [26].

Systemic exposure to TGR5 agonists increases gallbladder volume in mice [27]. Recently, an agonist of TGR5, FC-92-EC85, has been investigated in mice and dogs showing hepatobiliary and cardiovascular effects limit the utility of systemic TGR5 agonist in Diabetes [28]. a novel topical intestinal agonist of TGR5 that was given orally to obese and insulin-resistant mice, leading to a prominent elevation in GLP-1 levels along with significant improvement in glucose tolerance. Intestinal TGR5 agonist did not cause a significant change in gallbladder size in lean mice [29]. Thus, an ideal TGR5 agonist would be intestinal-specific agonist reaching $\mathrm{L}$ cells without affecting other systemic tissues [7]. However, the impact of the intestinal TGR5 agonist on human gallbladder remained unclear and the therapeutic potential for T2DM in the clinic needs to confirm in advance.

\section{Conclusion}

Decreased pruritus in cholestatic liver disease, improvement of insulin resistance in type 2 diabetes, protection against obesity, and inhibition of atheroma development have been suggested as the potential therapeutic targets of TGR5 agonist(s). However, it still remains in animal studies. Clinical trials are required to confirm whether the new semi-synthetic TGR5 agonists have clinical efficacy. Additionally, once the subtype TGR5 could be distinguished between the gallbladder and metabolic tissues, development of new agonist(s) would be easier in basic research.

\section{Acknowledgement}

We thank Miss Y.L. Yen for the kindly help in the collection of references.

\section{References}

1. Makishima M, Okamoto AY, Repa JJ, Tu H, Learned RM, et al. (1999) Identification of a nuclear receptor for bile acids. Science 284(5418): 1362-1365.

2. Lefebvre P, Cariou B, Lien F, Kuipers F, Staels B (2009) Role of bile acids and bile acid receptors in metabolic regulation. Physiol Rev 89(1): 147-191.

3. Ahlberg J, Angelin B, Bjorkhem I, Einarsson K (1977) Individual bile acids in portal venous and systemic blood serum of fasting man. Gastroenterology 73(6): 1377-1382.

4. Guo C, Xie S, Chi Z, Zhang J, Liu Y, et al. (2016) Bile Acids Control Inflammation and Metabolic Disorder through Inhibition of NLRP3 Inflammasome. Immunity 45(4): 802-816.

5. Benoit B, Meugnier E, Castelli M, Chanon S, Vieille-Marchiset A, et al. (2017) Fibroblast growth factor 19 regulates skeletal muscle mass and ameliorates muscle wasting in mice. Nat Med 23(8): 990-996.

6. Li T, Chiang JY (2014) Bile acid signaling in metabolic disease and drug therapy. Pharmacol Rev 66(4): 948-983.

7. Shapiro H, Kolodziejczyk AA, Halstuch D, Elinav E (2018) Bile acids in glucose metabolism in health and disease. J Exp Med 215(2): 383-396.

8. Katsuma S, Hirasawa A, Tsujimoto G (2005) Bile acids promote glucagon-like peptide-1 secretion through TGR5 in a murine enteroendocrine cell line STC-1. Biochem Biophys Res Commun 329(1): 386-390.

9. Kawamata Y, Fujii R, Hosoya M, Harada M, Yoshida H, et al. (2003) A G protein-coupled receptor responsive to bile acids. J Biol Chem 278(11): 9435-9440.

10. Wang YD, Chen WD, Huang W (2008) FXR, a target for different diseases. Histol Histopathol 23(5): 621-627.

11. Sato H, Genet C, Strehle A, Thomas C, Lobstein A, et al. (2007) Antihyperglycemic activity of a TGR5 agonist isolated from Olea europaea. Biochem Biophys Res Commun 362(4): 793-798. 


\section{Current Research in Diabetes \& Obesity Journal}

12. Lo SH, Li Y, Cheng KC, Niu CS, Cheng JT, et al. (2017) Ursolic acid activates the TGR5 receptor to enhance GLP-1 secretion in type 1-like diabetic rats. Naunyn Schmiedebergs Arch Pharmacol 390(11): 10971104 .

13. Wang LY, Cheng KC, Li Y, Niu CS, Cheng JT, et al. (2017) Glycyrrhizic acid increases glucagon like peptide-1 secretion via TGR5 activation in type 1-like diabetic rats. Biomed Pharmacother 95: 599-604.

14. Li Y, Cheng KC, Niu CS, Lo SH, Cheng JT, et al. (2017) Investigation of triamterene as an inhibitor of the TGR5 receptor: identification in cells and animals. Drug Des Devel Ther 11: 1127-1134.

15. Baggio LL, Drucker DJ (2007) Biology of incretins: GLP-1 and GIP. Gastroenterology 132(6): 2131-2157.

16. Trabelsi MS, Daoudi M, Prawitt J, Ducastel S, Touche V, et al. (2015) Farnesoid X receptor inhibits glucagon-like peptide-1 production by enteroendocrine L cells. Nat Commun 6: 7629.

17. Kumar DP, Rajagopal S, Mahavadi S, Mirshahi F, Grider JR, et al. (2012) Activation of transmembrane bile acid receptor TGR5 stimulates insulin secretion in pancreatic beta cells. Biochem Biophys Res Commun 427(3): 600-605.

18. Renga B, Mencarelli A, Vavassori P, Brancaleone V, Fiorucci S (2010) The bile acid sensor FXR regulates insulin transcription and secretion. Biochim Biophys Acta 1802(3): 363-372.

19. Kumar DP, Asgharpour A, Mirshahi F, Park SH, Liu S, et al. (2016) Activation of Transmembrane Bile Acid Receptor TGR5 Modulates Pancreatic Islet alpha Cells to Promote Glucose Homeostasis. J Biol Chem 291(113): 6626-6640.

20. Alejandro EU, Gregg B, Blandino-Rosano M, Cras-Meneur C, BernalMizrachi E (2015) Natural history of beta-cell adaptation and failure in type 2 diabetes. Mol Aspects Med 42: 19-41.

21. Zarrinpar A, Loomba R (2012) Review article: the emerging interplay among the gastrointestinal tract, bile acids and incretins in the pathogenesis of diabetes and non-alcoholic fatty liver disease. Aliment Pharmacol Ther 36(10): 909-921.

22. Watanabe M, Houten SM, Mataki C, Christoffolete MA, Kim BW, et al. (2006) Bile acids induce energy expenditure by promoting intracellular thyroid hormone activation. Nature 439(7075): 484-489.

23. Perino A, Pols TW, Nomura M, Stein S, Pellicciari R, et al. (2014) TGR5 reduces macrophage migration through mTOR-induced C/EBPbeta differential translation. J Clin Invest 124(12): 5424-5436.

24. Worthmann A, John C, Ruhlemann MC, Baguhl M, Heinsen FA, et al. (2017) Cold-induced conversion of cholesterol to bile acids in mice shapes the gut microbiome and promotes adaptive thermogenesis. Nat Med 23(7): 839-849.

25. Wang XX, Edelstein MH, Gafter U, Qiu L, Luo Y, et al. (2016) G ProteinCoupled Bile Acid Receptor TGR5 Activation Inhibits Kidney Disease in Obesity and Diabetes. Journal of the American Society of Nephrology 27(5): 1362-1378.

26. Pierre JF, Martinez KB, Ye H, Nadimpalli A, Morton TC, et al. (2016) Activation of bile acid signaling improves metabolic phenotypes in high-fat diet-induced obese mice. Am J Physiol Gastrointest Liver Physiol 311(2): G286-304.

27. Briere DA, Ruan X, Cheng CC, Siesky AM, Fitch TE, et al. (2015) Novel Small Molecule Agonist of TGR5 Possesses Anti-Diabetic Effects but Causes Gallbladder Filling in Mice. PLoS One 10(8): e0136873.

28. Bhat BG, LeeAnne M, Dean PP, Judit M, Shufang Z, et al. (2017) Hepatobiliary and Cardiovascular Effects Limit the Utility of Systemic TGR5 Agonists in Diabetes. J of Pharmacol \& Clin Res 3: 555623.

29. Lasalle M, Hoguet V, Hennuyer N, Leroux F, Piveteau C, et al. (2017) Topical Intestinal Aminoimidazole Agonists of G-Protein-Coupled Bile Acid Receptor 1 Promote Glucagon Like Peptide-1 Secretion and Improve Glucose Tolerance. 60(10): 4185-4211.

Your next submission with Juniper Publishers
will reach you the below assets
- Quality Editorial service
- Swift Peer Review
- Reprints availability
- E-prints Service
- Manuscript Podcast for convenient understanding
- Global attainment for your research
- Manuscript accessibility in different formats
( Pdf, E-pub, Full Text, Audio)
- Unceasing customer service
Track the below URL for one-step submission
https://juniperpublishers.com/online-submission.php

